\title{
Effective Processes for Quality Assurance
}

\author{
Dr. Boyd L. Summers* \\ Senior Software and Quality Assurance Consultant, BL Summers Consulting.LLC, Florence, Arizona, USA
}

${ }^{\star}$ Corresponding author: Senior Software and Quality Assurance Consultant, BL Summers Consulting.LLC, Florence, Arizona, USA; Email: bl.summers.consulting.llc@gmail.com

Received: January 23, 2019; Accepted: January 26, 2019; Published: February 01, 2019;

Quality Assurance will provide an understanding and importance for support in providing perspective and understanding from day to day activities and to provide effective and advocate a culture that supports commitment to customer integrity.

Index Terms - Delivery, Evaluations, Commitment, Consulting, Planning, Quality, Requirements, Audits, Evaluations, Verification and Validation.

\section{Introduction}

The primary purpose is to increase the implementation of Effective Processes for Quality Assurance for Companies and Institutions to increase communication, knowledge, and the visibility into the company operations. This journal will provide informative, interesting, and convey the methods for Quality Assurance to be more effective in current and future companies and institutions and could benefit as well by adopting these effective processes.

Driving innovation will help in controlling costs for companies, institutions, military programs, and successful businesses. Delivering complex products must have high quality to reduce customer problems and defects. Integration of Quality Assurance processes provides compliant work product management and gap analysis. The purpose of Quality Assurance is to provide a common operating framework in which best practices, improvements, and cost avoidance activities can be shared, and Quality Assurance responsibilities assigned results from converging on quality shared best practices are improved process execution and reduction of operational costs.

Quality Assurance personnel must support Business Companies by encouraging a cooperative, pro-active approach and ensure compliance through evaluations and management participation. All results are reported to management. Make sure that happens.

\section{Quality Management}

To have quality management in place it is simply, having documented paperwork, online instructions, execution with knowledgeable employees, monitoring or measuring and making continual improvements. The following improvements are to Plan and document to deliver results and Do implementation by a skilled work force. Always Check and Act to take actions and continually improve performance.

In order to have quality management implemented, the companies and institutions must be focused, process based, and improvement oriented. Say what you do, do what you say, prove it, and improve it. A quality management system can be used for internal application certifications and contractual purposes and the focus on the effectiveness of the quality management system in meeting customer requirements and expectations.

Do what you say: (Compliance): Follow all procedures and instructions that affect your work. You must say what you do (Documentation): Use current plans, procedures, and work instructions. Prove It: (Records): Demonstrate your work in accordance with compliant processes/procedures and provide objective evidence. Improve It: (Business Management/Continual Improvement and implement change based on information provided by Business Management.

"Managers do not control change but need to manage change." - Dr. Boyd L. Summers

\section{Policy}

A policy is the key element in business process and there are organizational, planning and control documentation and/or procedures to support key elements. The significant activities are defined in this book. To conduct a successful business, we should understand the scope of the work to be accomplished. A policy provides a mission statement of direction and guidance for companies and institutions. Policies are the highest level of authority and are consistent with the visions that should be used to be successful.

A very effective policy to review over and over is a policy for Quality Assurance. The policy states that we are the difference such as:

- I am personally responsible and accountable for the quality of my work.

- I acquire/use the necessary tools and skills needed to meet quality requirements.

- I know my objectives and needed process improvement goals.

\section{Quality Engineering}

Quality Engineering is associated with analysis, requirements understanding, and the importance of employer and/or consultant capabilities. Interfaces are defined externally and internal to ensure Quality Assurance is compatible supporting business activities and 
military programs. The Quality Engineering process methods are included in tasks or assignments to integrate all disciplines to meet all requirements and expectations. In years of working Defense and Space related to military and aerospace program technical Quality Assurance needs are very important.

Quality Engineering methods are used for application setting the ladder for rigorous business techniques to solve complex problems both technical and functional.

Driving innovation will help in controlling costs for companies, institutions, military programs, and successful businesses. Delivering complex products must have high quality to reduce customer problems and defects. Integration of Quality Assurance processes provides compliant work product management and gap analysis.

The purpose of Quality Assurance is to provide a common operating framework in which best practices, improvements, and cost avoidance activities can be shared, and Quality Assurance responsibilities assigned results from converging on quality shared best practices are improved process execution and reduction of operational costs.

Quality Assurance personnel must support Business Companies by encouraging a cooperative, pro-active approach and ensure compliance through evaluations and management participation. All results are reported to management. Make sure that happens.

\section{Lean and Agile}

Coming from a software and Quality Assurance technology background, I have supported many software companies, military and aerospace programs that are Lean and Agile and have a competitive advantage. By implementing these two principles, practices, development deliveries of products to the customers will show Quality Assurance has been applied and with fewer defects.

The definition of Lean is a new concept in the software world. Lean principals establish clear priorities by getting rid of bad multitasking, focus, and not finishing the task assigned to an individual within a business companies, military and aerospace programs. Lean principals will eliminate the release of software being late and require an early delivery. One must prepare, start, finish, and use checklists to prevent software defects and risk. Teams will face issues and resolve them on timely basis and drive daily software execution and quality products.

Applying the Agile management model per Figure 1 implements software development, supports many initiatives, and provides a Business Company and Institutions a strong management approach to emphasize short-term planning, risk mitigation, and adaptability to changes as well as close collaboration with the customers.

\section{Proactive Approach to Quality Assurance}

The elements of basic standards require identification to plans and procedures for production and service which can affect Quality Assurance processes. There are elements that should always be addressed. These elements are:

- All plans and documents show how work is done

- Effective tools for handling work used in a working environment
- Compliance to monitor and control work products

- Approval of Quality Assurance processes

What Quality Assurance auditors should always assess the operations and where all the work is done. The auditors need to talk to personnel and ensure they have the training and experience and the knowledge for process control for all data documentation. The auditors will interview personnel and ask about the workmanship activities, specifications and tie them to records. Education and training of personnel are the required standards and mush always be correct. The standards offer ways to address specific processes by continuous monitoring of all processes.

All Quality Assurance auditors need to demonstrate the capability to deliver effective and efficient data. There should always be an ongoing program for training to stay current and show improvement to satisfy customer needs.

Quality Assurance consultants must support by encouraging companies, institutions, military and aerospace programs, and successful businesses to be cooperative and a pro-active approach to quality and ensure process compliance through evaluations and management participation.

Compliance verification is performed using quality evaluations, assessments, reviews, or appraisals. Quality Assurance consultant's witnesses/monitors activities in accordance with the project-level reviews and meetings.

\section{Quality Management System}

The Quality Management System (QMS) is a requirement to have processes documented and execute with knowledgeable people and teams. At times metrics are reviewed and monitored to ensure processes are showing improvement. I will have a chapter that defines and talks about metrics and a very good understanding of the importance of metrics and how they come into play with Quality Assurance.

All customer focus should be QMS and provide the framework that is followed to say; what you do, do what you say, prove it, and show improvement. The Standards for QMS is AS9100 AS9100C, AS9100D, SAE AS9110, and ISO 900 and is the model for:

- Quality Assurance

- Design and Development

- Production and Delivery Results

- Business Compliances

- Customer Contracts

\section{Biography}

Boyd L. Summers has completed his Bachelor of Science (BS), Business Administration at Weber State University, USA. Areas of emphasis: Information Systems, Production and Operations Management, Quantitative Analysis and Methods, Human Resources, Economics, Business Management and Statistical Analysis and Computer Science. 
He is a Software Technology and Quality Consultant for BL Summers Consulting LLC located in Florence, Arizona. With 30 years of experience in Software Engineering and a leader of multiple software development teams, Boyd continues to solve complex technical challenges to ensure that system and software engineering problems are addressed, resolved and include: System Design, Software Requirements, Software Design, Software Test and Evaluation, Configuration Management, Quality Assurance, Process and Product evaluations. Applies Processes in Agile, Lean and SixSigma including a Software Technology Speaker at conferences and member of the American Society Quality (ASQ).

Author of the three software and quality technology books titled; "Software Engineering Reviews and Audits." and "Effective Methods for Software and Systems Integration. and Effective Process for Quality Assurance and Provides Software and Quality Articles to Journals and magazines. 